\title{
The Relationship between Thyroid Autoantibody and Fertilization Outcome in First Time in Vitro Fertilization
}

\author{
Myungsin Kim, M.D., Myung Gu Jung, M.S., Yuri Jo, M.D., Eun Jeong Jang, M.D.*, \\ Kyu Hyun Kim, M.D.
}

Reproductive endocrinology, Maria Fertility Hospital, Bucheon, Gyeong-gi, Korea

${ }^{*}$ Reproductive endocrinology, Maria Fertility Hospital, Pyungchon, Gyeong-gi, Korea

PROBLEM STATEMENT The presence of thyroid autoantibodies (TAA) is related to fertility problems and there have been researches that showed the impact of TAA on in vitro fertilization and embryo transfer (IVF-ET) outcomes. However, most of their results were limited in the outcomes after embryo implantation. The aim of this study was to investigate the impact of TAA on fertilization rate and embryo qualities before embryo implantation.

MATERIALS AND METHODS Retrospectively, we analyzed the women who underwent their first-time IVF-ET cycles from January 2015 to December 2016. The patients who had the infertility cause of male factor and abnormal findings of semen analysis on the fertilization day were excluded. A total 487 patients were included and 34 patients had positive results of TAA, whereas 453 patients had negative results of TAA.

RESULTS Mean age, AMH, TSH, fT4 levels and the duration of infertility of both groups were similar. There were no significant differences between the groups in terms of total number of retrieved oocytes, the number of metaphase II and metaphase I oocytes, the ratio of intracytoplasmic sperm injection (ICSI). Statistically, differences of total fertilization rate (68.9\% vs. $69.8 \%, p=0.760)$, fertilization rate with ICSI $(84.2 \%$ vs. $79.2 \%, p=0.244)$, fertilization rate of conventional IVF $(62.1 \%$ vs. $65.8 \%, p=0.278$ ) and the ratio of good quality embryos (13.6\% vs. $14.4 \%, p=0.760)$ were not found.

CONCLUSION There was no significant difference in the outcomes of fertilization following IVF-ET in the patients with TAA when compared with those negative for TAA. Thyroid autoantibody status did not affect fertilization outcomes in women with their first time in Vitro Fertilization in this study.

Table1. Basic Characteristics of Patients

\begin{tabular}{|c|c|c|c|}
\hline & $\begin{array}{c}\text { Thyroid } \mathbf{A b}(+) \\
(\mathbf{n = 3 4 )}\end{array}$ & $\begin{array}{c}\text { Thyroid Ab(-) } \\
(\mathbf{n = 4 5 3 )}\end{array}$ & P-value \\
\hline Mean age (years) & $34.4 \pm 4.7$ & $34.8 \pm 4.0$ & NS \\
\hline AMH (ng/mL) & $3.9 \pm 3.5$ & $4.1 \pm 3.8$ & NS \\
\hline TSH (ulU/mL) & $2.7 \pm 1.9$ & $2.3 \pm 1.4$ & NS \\
\hline FreeT4 $(\mathrm{ng} / \mathrm{dL})$ & $1.3 \pm 0.3$ & $1.3 \pm 0.9$ & NS \\
\hline $\begin{array}{c}\text { Duration of } \\
\text { Infertility (months) }\end{array}$ & $37.7 \pm 25.3$ & $30.0 \pm 27.5$ & NS \\
\hline
\end{tabular}

Table2. Reproductive outcomes according to TAA

\begin{tabular}{|c|c|c|c|}
\hline & $\begin{array}{c}\text { Thyroid } \\
\mathbf{A b}(+)\end{array}$ & $\begin{array}{c}\text { Thyroid } \\
\mathbf{A b}(-)\end{array}$ & $\begin{array}{c}\text { P. } \\
\text { value }\end{array}$ \\
\hline Average No. of Oocytes & $9.5 \pm 6.3$ & $10.2 \pm 6.7$ & NS \\
\hline Average No. of MII Oocytes & $7.4 \pm 5.0$ & $7.9 \pm 5.3$ & NS \\
\hline $\begin{array}{c}\text { Average No. of Ml Oocytes } \\
\text { Average No. of Oocytes for } \\
\text { ICSI }\end{array}$ & $1.7 \pm 1.2$ & $1.8 \pm 1.1$ & NS \\
\hline $\begin{array}{c}\text { Average No. of Oocytes for } \\
\text { Conventional IVF }\end{array}$ & $7.4 \pm 5.6$ & $4.4 \pm 2.6$ & NS \\
\hline
\end{tabular}

Table3. Fertilization outcomes according to TAA

\begin{tabular}{|c|c|c|c|}
\hline & $\begin{array}{c}\text { Thyroid } \\
\text { Ab(+) }\end{array}$ & $\begin{array}{c}\text { Thyroid } \\
\text { Ab(-) }\end{array}$ & P-value \\
\hline Total Fertilization Rate (\%) & $68.9(\%)$ & $69.8(\%)$ & 0.760 \\
\hline $\begin{array}{c}\text { Fertilization Rate with } \\
\text { ICSI (\%) }\end{array}$ & $84.2(\%)$ & $79.2(\%)$ & 0.244 \\
\hline $\begin{array}{c}\text { Fertilization Rate with } \\
\text { Conventional IVF (\%) }\end{array}$ & $62.1(\%)$ & $65.8(\%)$ & 0.278 \\
\hline
\end{tabular}

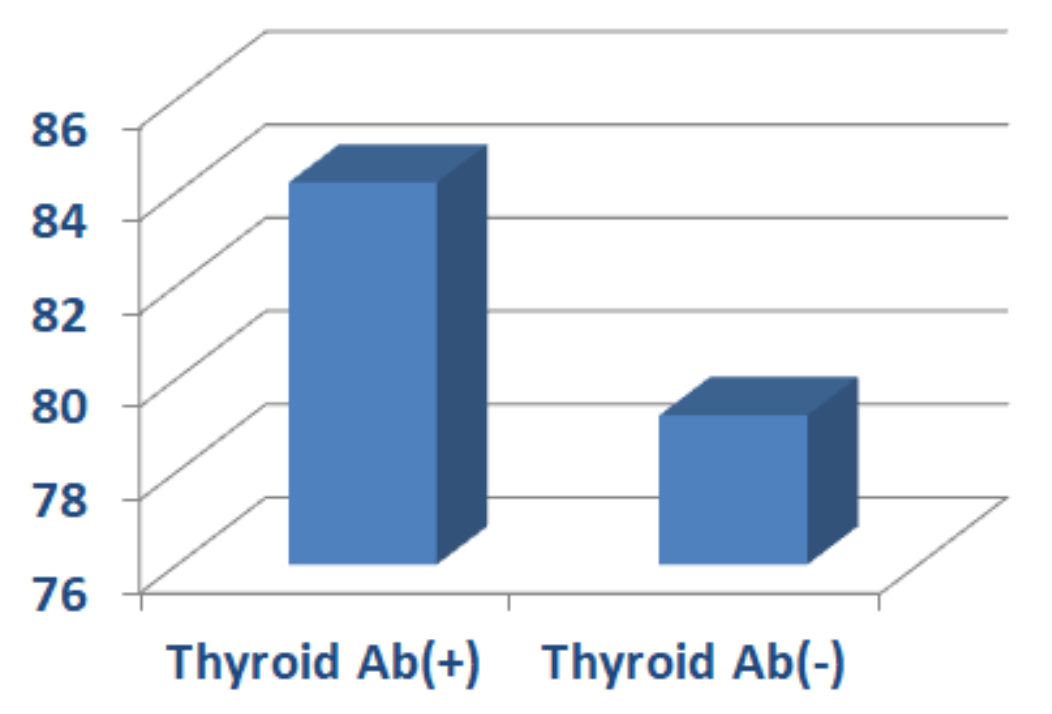

Figure 1. Fertilization rate with ICSI (\%)



Figure 2. Fertilization rate with conventional IVF (\%)

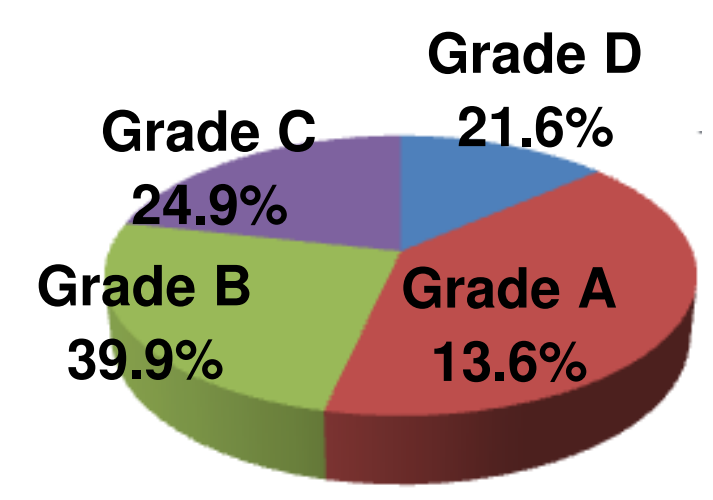

Thyroid $\mathrm{Ab}(+)$

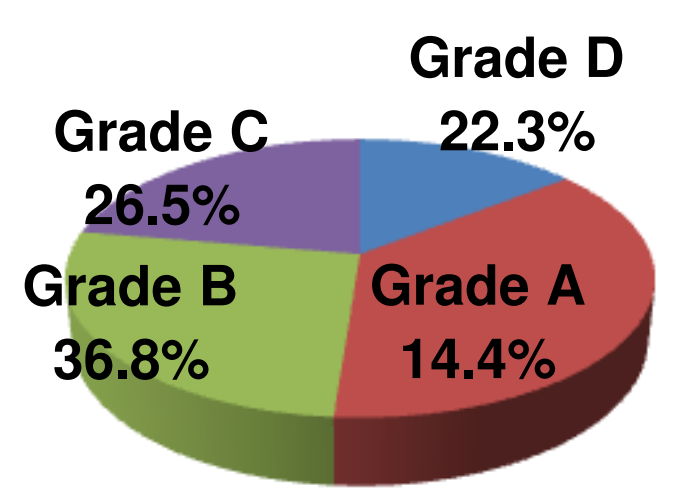

Thyroid Ab(-)
Figure 3. Grading of Day3 Embryos (\%) 